\title{
Effect of surface roughness on susceptibility of Escherichia coli biofilm to benzalkonium chloride
}

\author{
Mohammed Jibrin Ndejiko a, Wan Rosmiza Zana Wan Dagang b, ${ }^{\text {* }}$ \\ a Department of Microbiology, Ibrahim Badamasi Babangida University, PMB 11, Lapai, Nigeria \\ b Faculty of Biosciences and Medical Engineering, Universiti Teknologi Malaysia, 81310 Skudai, Johor Bahru, Johor, Malaysia \\ * Corresponding author: rosmiza@fbb.utm.my
}

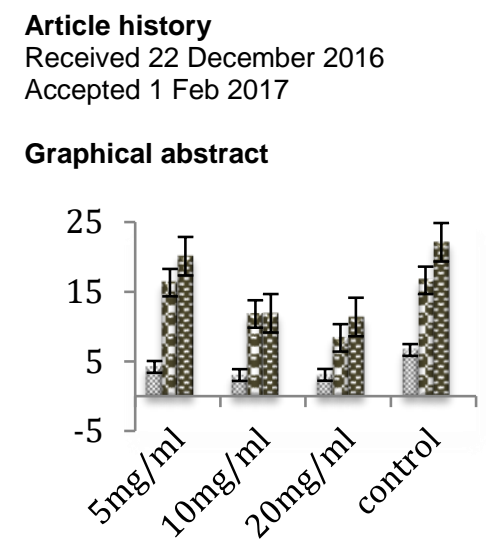

\section{Article history}

Graphical abstract

\begin{abstract}
The inherent natural tendency of bacteria to adhere and form biofilm on both biotic and abiotic surfaces and the consequential resistance to antimicrobial treatments remained a major concerned to humanity. The surface roughness of the sand blasted and cleaned stainless steel (type 304) substrates were measured using 3D measuring laser microscope before biofilm were developed on different surface roughness under continuous nutrient supply. The effect of benzalkonium chloride (BKC) as antibacterial agent on the biofilms was investigated. A concentration of $5 \mathrm{mg} / \mathrm{mL}$ BKC exert no pronounced effect on the biofilm formed on the three surfaces as compared to the $10 \mathrm{mg} / \mathrm{mL}$ and 20 $\mathrm{mg} / \mathrm{mL}$ that removed approximately $50 \%$ of the cells from the respective surfaces. Conversely, the overall effect of the three concentrations tested were significantly higher $(p \leq 0.05)$ on the stainless steel coupon with the least average surface roughness of $0.38 \pm 1.5 \mu \mathrm{m}$. These observations support the hypothesis that surface profile is one of the factors that influence biofilm susceptibility to antibacterial agents and reinforced the wide spread observation that microorganisms living as biofilm tends to be resistance to antimicrobial treatment especially at lower concentrations of $5 \mathrm{mg} / \mathrm{mL}$.
\end{abstract}

Keywords: Biofilm, benzalkonium chloride, surface roughness

\section{INTRODUCTION}

Microbial adhesion to surfaces and consequent biofilm formation has been documented in different environments. Biofilm is a natural tendency of microorganisms to attach to wet surfaces, multiply and embedded themselves in a slimy matrix composed of extracellular polymeric substances (EPS). The ability of microorganisms to form biofilms on the surfaces of utensils and other equipment used in domestic kitchen raises the possibilities that infection may occur following the cross contamination of freshly prepared foods in domestic kitchens. Outbreak of food borne pathogens such as Escherichia coli and Listeria monocytogens, Yersiniaenterocolitica, Campylobacterjejuni, Salmonella spp., Staphylococcus spp. and storage bacteria such as Pseudomonas spp. enhance resistance to antibiotic or sanitizers when cells are in biofilms [1-3].

Direct microscopic examinations and quantitative recovery techniques used to study biofilms revealed that more than $99.9 \%$ of the bacteria live as biofilms on a wide range of surfaces [4]. These solid surfaces become more vulnerable to biofilm formation when they are submerged in nutrient rich liquids or in contact with water for a long period of time. In order to combat biofilms, surface disinfection is normally carried out by applying liquid chemical disinfectants to food contact and non-food contact surfaces [5]. The microbicidal activity of commercial antimicrobial agents is largely based on quaternary ammonium compounds, phenolic compounds, organic acids, alcohol, chlorine and iodophores $[2,6]$.
Despite the use of disinfectants, significant number of researches has documented the persistence of some food borne pathogens on food contact surfaces especially when they are in biofilms [7], thereby affecting the quality and safety of the food products. The resistance of the biofilms to the antimicrobials have been linked to several mechanism including but not limited to little or no infiltration of antibacterial agent through the EPS [4]. This is due to binding action between the positively charged and negatively charged ions of the antimicrobial agents and the EPS $[8,9]$. The retardation of the growth rate by the biofilm microorganisms consequently affects the action of antimicrobials which required vigorous microbial growth, physiological changes, development and transfer of resistance phenotypes among the organisms in biofilm. In addition, the alteration of microenvironment can also antagonized the effect of antimicrobials due to nutrient or waste accumulation [10-12].

Furthermore, to avoid contamination of freshly prepared food by pathogenic organisms there is need for efficient use of antimicrobial agents or sanitizers on domestic kitchen surfaces. Many of the commercial antimicrobials currently in use in domestic kitchens have been found to be effective against microbial suspensions. However their effectiveness against biofilm adherence to food contact surfaces and kitchen utensils has not been fully evaluated. Therefore, study of effect of commercial antimicrobial agents on biofilm formation is a necessary requirement in combating biofilm formation by the pathogenic organisms. The results of this study will go a long way in addressing the problems face in eradication of biofilms on domestic kitchen surfaces. It will also point out suggestions on the dose and 
exposure time of commercial antimicrobial agents that should be applied to food contact surfaces.

\section{EXPERIMENTAL}

\section{Preparation of the stainless steel}

The stainless steel (SS) (Type 304 no. 4 finish) was selected as substratum for growing biofilm because it is the most widely used due to its high corrosion resistance in diverse environment. The SS was obtained from CK Stainless Steel work (Johor, Malaysia) and cut into 20 pieces of coupons with $10 \mathrm{~mm}$ diameter $\mathrm{x} 2 \mathrm{~mm}$ thickness. Three of the SS coupons were left unmodified while different roughness profiles were created on the other stainless steel coupons using a sandblasting machine (MHG Strhlanlegen, UTM). A sandblasting machine was generally used to clean and abrade surfaces of rusting, paints or any undesired surface materials using silica sand. Briefly, the coupons were mounted to a plier with the useful surface facing up and an air powered pressure gun was used to fire out the silica sand at high speed whilst directing it to the surface of the coupon held in the pliers. Different roughness was maintained on each sets of the stainless steel by sandblasting them for $3 \mathrm{~min}$ and five min respectively.

All the SS coupons were washed with a detergent solution for 20 min and rinsed three times in $15 \mathrm{~mL}$ of sterile deionised water while agitating using a vortex. The coupons were sterilized by exposing them to UV light for 60 minutes. Subsequently, the coupons were degreased in alcohol for $1 \mathrm{~h}$ and rinsed with deionised water using a vortex before they were finally dried in a laminar air flow cabinet following the procedure demonstrated by [28].

\section{Measurement of the surface profile}

The surface roughness of the sand blasted and cleaned SS substrates were measured using 3D measuring laser microscope (Olympus LEXT OLS4100, Crest Systems (M) Sdn. Bhd). The images were acquired using a 50X objective lens, covering a total area of $256 \mu \mathrm{m} \times 256 \mu \mathrm{m}$. The line roughness $\left(R_{a}\right)$ which considers the average roughness was acquired in addition to the 3D image. The standard deviations of the mean (SD) from the data obtained were determined.

\section{Effect of Benzalkonium Chloride on the biofilm}

Benzalkonium chloride (BKC) (Fluka) was used to study the effect of commercial antimicrobial agents on biofilms. Its application in wide range of commercial disinfectant formulations, such as being the active component of Dettol and Lysol are commonly used for surface disinfections. In order to study the effect of BKC, the biofilms of $E$. coli DH5 $\alpha$ was grown in continuous flow system. Initially, the E. coli DH5 $\alpha$ colony from the slant agar bottle prepared from late log phase was grown on Luria Bertani (LB) agar for $24 \mathrm{~h}$. A colony from LB agar was subsequently grown in $100 \mathrm{~mL} \mathrm{LB}$ broth at $37^{\circ} \mathrm{C}$. The culture obtained was used in a volume of $10 \%$ of the medium bottle as the inoculum for the biofilm formation as previously demonstrated by Jayaraman [13] and Soleimani et. al. [14]. The peristaltic pump (Watson marlow 120U/R) was used to pump the culture medium through the home-made flow cell at flow rate of $1 \mathrm{rpm}$ for $72 \mathrm{~h}$. Throughout the experimental period, the culture medium was stirred using a magnetic stirrer to ensure the efficiency of oxygen dispersion in liquid media [14]. After $72 \mathrm{~h}$, the attached biofilm was rinsed by flowing PBS to remove loosely bound cells and the media. Then, the system was perfused with $5 \mathrm{mg} / \mathrm{mL}$ of BKC whilst running the pump at $10 \mathrm{rpm}$ for $30 \mathrm{~min}$ following the techniques demonstrated by Romanova et. al.[15]. After the exposure time, the system was further rinsed with sterilized PBS to wash out and neutralized the residual BKC. The number of attached organisms that survive the effect of the BKC was determined via cell viability on the coupons. The same procedure was repeating using $10 \mathrm{mg} / \mathrm{mL}$ and $20 \mathrm{mg} / \mathrm{mL}$ of the BKC. However, in the case of higher concentrations of BKC, $100 \mu \mathrm{L}$ of the initial suspensions were plated on LB agar without dilution and incubated overnight at $37{ }^{\circ} \mathrm{C}$. The control experiment was conducted by perfusing the system with sterilised distilled water without the BKC for $30 \mathrm{~min}$ after the initial rinsing with the PBS solution. The percentage bacterial removal was calculated using equation the equation below:

$\mathrm{M}(\%)=[(\mathrm{NTVC}-\mathrm{NVC}) / \mathrm{NTVC}] \times 100$
Where $\mathrm{M}$ is the percentage of bacteria removed, NTVC is a number of total adhered cells in CFU/mL and NVC is a number of viable cells after treatment with corresponding concentration of $\mathrm{BKC}$ in $\mathrm{CFU} / \mathrm{mL}$, respectively.

\section{Statistical analysis}

The data generated were subjected to statistical analysis using the popular SPSS version 18. P-Values less than 0.05 were considered significant.

\section{RESULTS AND DISCUSSION}

\section{Stainless steel surface topography}

The roughness images of each SS coupon were taken from four different points using 3D measuring laser microscope (Olympus LEXT OLS4100). Mean value of surface roughness of each of the three SS surfaces measured in triplicate are presented in the Table 1. The figures after \pm represent the standard error of the mean (SEM) from three independent SS surfaces which give a total of 9 measurements. Figure 1 to 3 show the representative OLS4100 micrograph of each of the SS coupons and the corresponding 3D images. The major parameter normally used in comparison of surface profile is the average roughness $\left(R_{a}\right) . R_{a}$ represents the arithmetic mean deviation of the unconditional ordinate values obtained from a given sampling length[16]. It is also worth mentioning that surface roughness of less $0.8 \mu \mathrm{m}$ ( which is also the industrial threshold) is recommended to minimize fouling and microbial contamination of surfaces [17-19].

As shown in the figures, the roughness profile increases from SS-1 to SS-3. However, the SS- 2 and SS-3 contains some crevasses and cracks with high peaks. Such cracks and crevasses were hardly cleaned and therefore were capable of harbouring more bacterial cells than the SS1 that appear smoother except for little imperfections [20].

\section{Effect of Benzalkonium chloride (BKC) concentration}

The effect of BKC concentration on the biofilms was estimated as a percentage removal, $\mathrm{M}(\%)$ based on the number of cells recovered from the coupons after the exposure to BKC. Figure 4 indicates that no pronounced effect was observed after exposure to $5 \mathrm{mg} / \mathrm{mL}$ of BKC. Pronounced effect of BKC on the biofilm was observed with $10 \mathrm{mg} / \mathrm{mL}$ and $20 \mathrm{mg} / \mathrm{mL}$. However, these concentrations do not completely remove the biofilms from the SS surface. These observation reinforced the wide spread report that microorganisms living in biofilm are generally resistance to antimicrobial treatments and underscore the adequacy of lower concentrations of BKC and other antimicrobial agents in removing microbial biofilms.

The resistance of biofilm cells to antimicrobial concentration has been linked to several factors. For example, slow growth of biofilm organisms that lead to poor expression of antimicrobial binding proteins and insensitive to antimicrobials that require vigorous bacterial multiplication [11]. EPS has been reported to reduce the potency of antimicrobial agents on the biofilms by diluting the antimicrobial concentration there by allowing little or no concentration to reach the cells depending on the concentration of the antimicrobial agent $[8,21]$. BKC, being positively charged Quaternary ammonium compound (QAC) can also interact with negatively charged extracellular material that surrounds the biofilm and consequently reduce the penetration of the BKC. Based on these observations, the insignificant effect of the lower concentration $(5 \mathrm{mg} / \mathrm{mL})$ observed in this study may be attributed to the ability of the EPS to dilute this concentration thereby reducing their potency against the E. coli DH5 $\alpha$ biofilms.

Furthermore, QACs have generally been demonstrated to exert only a bacteriostatic effect at lower dose. Whilst, the bactericidal activity can only be achieved at high concentrations [22, 23]. Therefore, the use of lower dose is capable of inducing development of resistance by the microorganisms most especially when they are entrapped in biofilms structure. Development of resistance by microorganisms including $E$. coli and $P$. aeruginosa as a consequential effect of continuous exposure to sub lethal doses has been reported in several literatures [24, 25].

In another development, there have been reports that QACs such as BKC are capable of disrupting the outer membrane and consequently 
leak out the intracellular components of gram negative organisms [26]. Consequently, one may inferred that $10 \mathrm{mg} / \mathrm{mL}$ and $20 \mathrm{mg} / \mathrm{mL} \mathrm{BKC}$ that shows significant effect on the E. coli DH5 $\alpha$ biofilms in this study were able to overcome the barriers created by the EPS and thus able to disrupt the outer membrane of the cells within the biofilm.

\section{Effect of Surface Roughness on the Effectiveness of the Benzalkonium Chloride}

The effect of surface roughness on the efficiency of the BKC was determined by comparing the cell removal percentage for each concentration. Table 2 shows that high percentage of $36 \%, 54 \%$ and $53 \%$ were removed with $5 \mathrm{mg} / \mathrm{mL}, 10 \mathrm{mg} / \mathrm{mL}$ and $20 \mathrm{mg} / \mathrm{mL}$ respectively from the substrate with the least surface roughness $(0.38 \pm$ $0.15 \mu \mathrm{m})$ followed by $1.5 \pm 0.18 \mu \mathrm{m}$ and $2.0 \pm 0.09 \mu \mathrm{m}$. Though the percentage of cell removal of the three concentrations from the SS-3 with the highest roughness of $2.0 \pm 0.09 \mu \mathrm{m}$ were slightly higher than those of the SS-2 with roughness of $1.5 \pm 0.18 \mu \mathrm{m}$. Statistical comparison of the number of cells that remained attached to the three surfaces after their exposure to $20 \mathrm{mg} / \mathrm{mL}$ BKC also show a very significant effect $(\mathrm{p} \leq 0.05)$ on the SS with the least roughness. These observations reinforced the view that surviving bacteria might hide in cracks and fissures in the rougher surfaces [27] and hence one may conclude that surface topography does not only determined the extent of biofilm formation on stainless steel, but also influence biofilm susceptibility to antimicrobial treatment.

Table 1 Mean surface roughness of the three sets of stainless steel

\begin{tabular}{lc}
\hline Stainless steel sample & Surface roughness $(\boldsymbol{\mu m}) \pm$ SEM \\
\hline Stainless steel 1(SS1) & $0.38 \pm 0.15$ \\
Stainless steel 2 (SS2) & $1.5 \pm 0.18$ \\
Stainless steel 3 (SS3) & $2.0 \pm 0.09$ \\
\hline
\end{tabular}

Table 2 Percentage bacteria removal from stainless steel coupons with different BKC concentrations

\begin{tabular}{lccc}
\hline $\begin{array}{l}\text { Stainless steel surface } \\
\text { roughness }(\boldsymbol{\mu m})\end{array}$ & \multicolumn{3}{c}{$\begin{array}{l}\text { Percentage (\%) bacteria removal at } \\
\text { different BKC concentrations }\end{array}$} \\
\cline { 2 - 4 } & $5 \mathrm{mg} / \mathrm{mL}$ & $10 \mathrm{mg} / \mathrm{mL}$ & $20 \mathrm{mg} / \mathrm{mL}$ \\
\hline $\mathbf{0 . 3 8} \pm \mathbf{0 . 1 5} \quad(\mathbf{S S 1})$ & 36 & 54 & 53 \\
$\mathbf{1 . 5} \pm \mathbf{0 . 1 8}$ (SS2) & 5 & 29 & 50 \\
$\mathbf{2 . 0} \pm \mathbf{0 . 0 9}(\mathbf{S S 3})$ & 9 & 46 & 49 \\
\hline
\end{tabular}
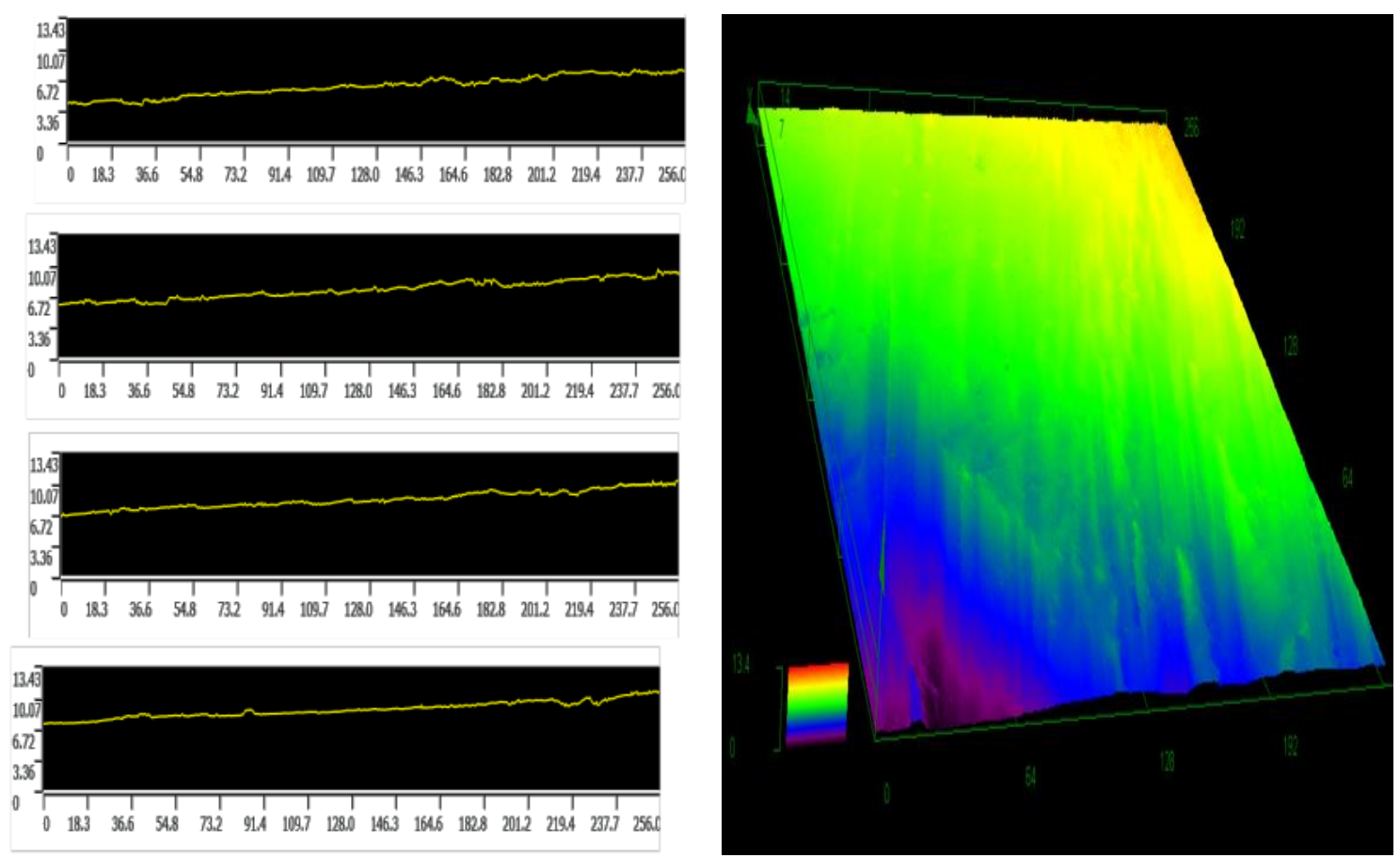

Figure 1 A representative micrograph of surface roughness profile of the SS-1 with the corresponding 3D image. The mean value of the surface roughness was found to be $0.38 \pm 0.15 \mu \mathrm{m}$. The colours show height difference at each point with the red been the highest point and the purple been the inner most depth. 

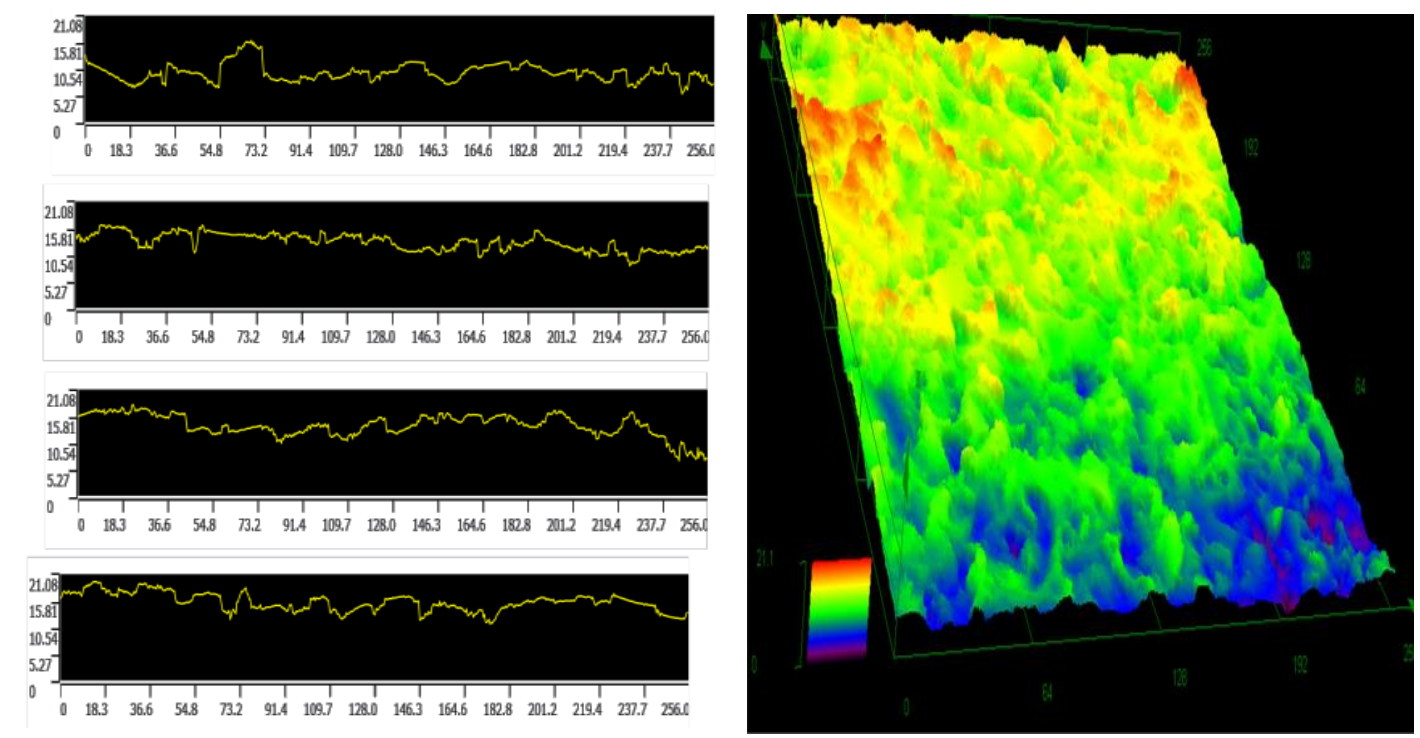

Figure 2: A representative micrograph of surface roughness profile of the triplicate SS-2 with the corresponding $3 \mathrm{D}$ images. The mean value of the surface roughness was found to be $1.5 \pm 0.18 \mu \mathrm{m}$. The colours show height difference at each point with the red been the highest point and the purple been the inner most depth.
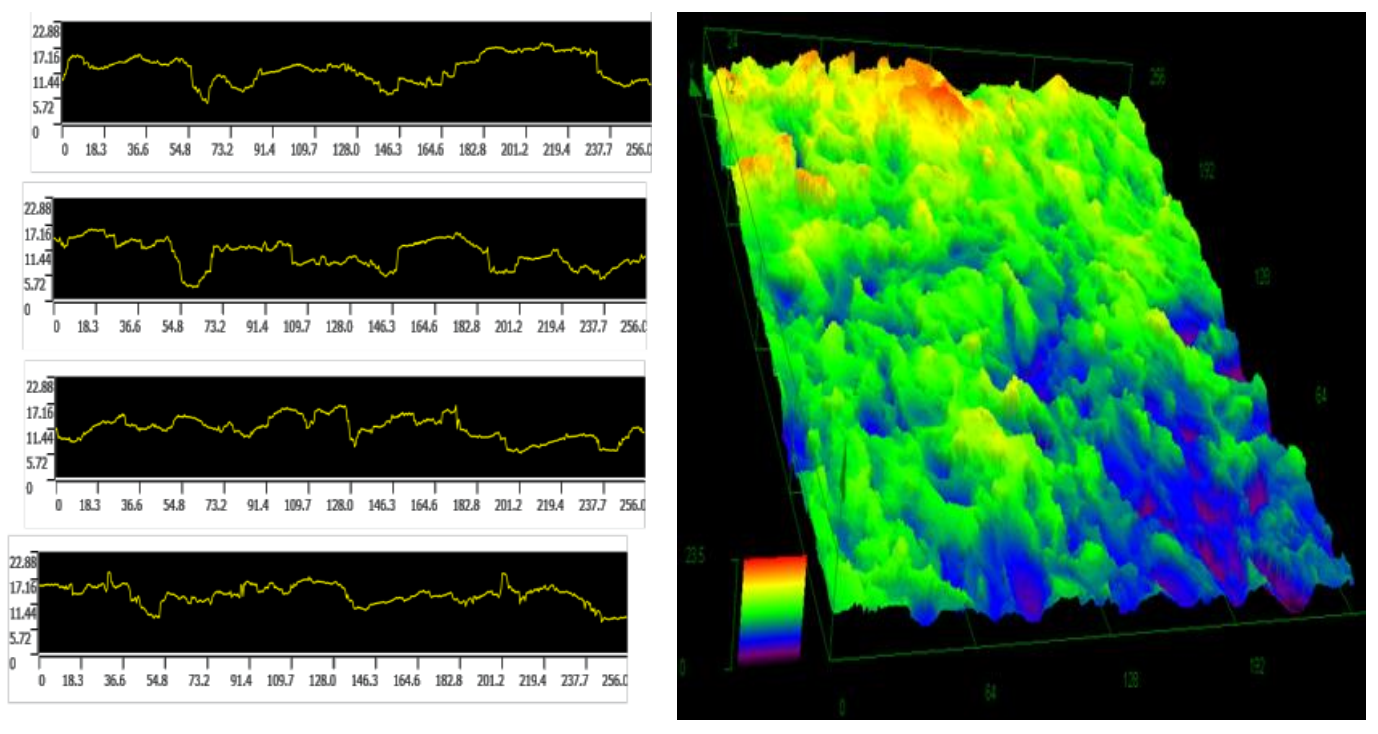

Figure 3: A representative micrograph of surface roughness profile of the triplicate SS-3 with the corresponding 3D image. The mean value of the surface roughness was found to be $2.0 \pm 0.09 \mu \mathrm{m}$. The colours show height difference ateach point with the red been the highest point and the purple been the inner most depth.

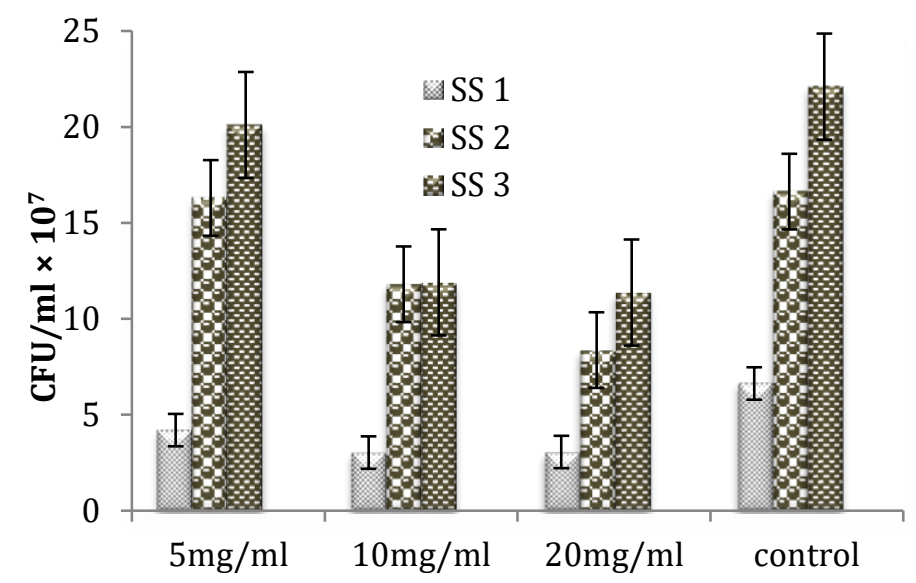

Figure 4 The bacteria recovered after exposure of the stainless steels to the corresponding concentration of BKC. 


\section{CONCLUSION}

The investigation of biofilms sensitivity to BKC concentrations revealed that more biofilm can be removed with $10 \mathrm{mg} / \mathrm{mL}$ and 20 $\mathrm{mg} / \mathrm{mL}$. All the three concentrations of BKC tested were more effective on the biofilms grown on the coupon 1 with the least $R_{a}$ value as compared to other two coupons indicating surface topography has influence on efficiency of antibacterial agents in removing biofilms. Overall, the results of this study indicate that surface roughness does not only determine the extent of biofilm formation of $E$. coli DH5 $\alpha$ on stainless steel, but also influence biofilm susceptibility to antimicrobial treatment especially with benzalkonium chloride.

\section{AKNOWLEDGEMENT}

The authors would like to give thanks to Ministry of Education Malaysia (MOE), Universiti Teknologi Malaysia and Potential Academic Staff Grant (Q.J130000.2745.00K41) for their financial support.

\section{REFERENCES}

[1] Kim, H., Ryu, J-H. and Beuchat, L. R., Effectiveness of disinfectants in killing Enterobacter sakazakii in suspension, dried on the surface of stainless steel and in a biofilm. Applied and Environmental Microbiology, 2007. 73 (4): p. 1256-1265.

[2] Simões. M, Simões, L. C. and Vieira, M. J., A review of current and emergent biofilm control strategies. LWT - Food Science and Technology, 2010. 43: p. 573-583.

[3] Ndejiko, M. J. and Wan Rosmiza, W. D., Methods and protocol flow cells: technique used for studying microbial biofilms. Jurnal Teknologi, 2016. 78 (2): p. 1-5.

[4] Giaouris, E., Chorianopoulos, N., Skandamis, P. and Nychas, G-J., 2012 Attachment and biofilm formation by Salmonella in food processing environments in Barakat S. M. Mahmoud. (157-180). Croatia: Intech Open Access Publisher.

[5] Frank, J. F., Microbial attachment to food and food contact surfaces. Advances in Food and Nutrition Research, 2001. 43: p. 319-370.

[6] Raya, A., Fundamental study of the initial bacterial attachment of Pseudomonas aeruginosa, Pseudomonas putida and Escherichia coli. 2009, The University of Akron.

[7] Wong, H. S., Townsend, K. M., Fenwick, S. G., Maker, G., Trengove, R. D. and O'Handley, R. M., Comparative susceptibility of Salmonella Typhimurium biofilms of different ages to disinfectants. Biofouling, 2010. 26 (7) : p. 859-864.

[8] Bose, S. and Ghosh, K. A., A challenge to medical science. Journal of Clinical and Diagnostic Research, 2011.5 (1) : p. 127-130.

[9] Ndejiko, M. J., Abubakar, B. M., Yusuf, H., Sulaiman, M., Saidu, H., Idris, A. and Tijani, H., Bacterial biofilm: a major challenge of catheterization. Journal of Microbiology Research, 2013. 3 (6): p.213-223.

[10] Stewart, P. S., Mechanisms of antibiotic resistance in bacterial biofilms. International Journal of Medical Microbiology, 2002. 292 (2) : p. 107-113.
[11] Cox, G. and Wright, G. D., Intrinsic antibiotic resistance:Mechanisms, origins, challenges and solutions. International Journal of Medical Microbiology, 2013. 303(6): p. 287-292.

[12] Sircar, S. and Bortz, D. M., Sticky bacteria: adhesion-detachment based microbial aggregation dynamics. arXiv preprint arXiv:1301.2504, 2013.

[13] Jayaraman, A., Cheng, E. T., Earthman, J. C. and Wood, T. K., Axenic aerobic biofilms inhibit corrosion of SAE 1018 steel through oxygen depletion. Applied Microbiology and Biotechnology, 1997. 48 (1): p. 1117.

[14] Soleimani, S., Ormeci, B. and O. B. Isgor, Growth and characterization of Escherichia coli DH5a biofilm on concrete surfaces as a protective layer against microbiologically influenced concrete deterioration (MICD). Applied Microbiology and Biotechnology, 2013. 97 (3) : p. 1093-1102.

[15] Romanova, N. A., Gawande, P. V., Brovko, L. Y. and Griffiths, M. W., Rapid methods to assess sanitizing efficacy of benzalkonium chloride to Listeria monocytogenes biofilms. Journal of Microbiological Methods, 2007. 71 (3) : p. 231-237.

[16] Schlisselberg, Dov B. and Yaron, S., The effects of stainless steel finish on Salmonella Typhimurium attachment, biofilm formation and sensitivity to chlorine. Food Microbiology, 2013. 35 (1): p.65-72.

[17] Flemming, H. C. and Wingender J., The biofilm matrix. Nature Reviews Microbiology, 2010. 8 (9) : p. 623-633.

[18] Abban, S., Jakobsen, M. and Jespersen, L., Attachment behaviour of Escherichia coli K12 and Salmonella Typhimurium P6 on food contact surfaces for food transportation. Food Microbiology, 2012. 31 (2) : p. 139147.

[19] Johnson, D. and Hilal, N., Characterisation and quantification of membrane surface properties using atomic force microscopy: A comprehensive review. Desalination, 2015. 356: p.149-164.

[20] Boyd, R. D., Verran, J., Hall, K. E., Underhill, C., Hibbert, S. and West, $\mathrm{R}$, The cleanability of stainless steel as determined by X-ray photoelectron spectroscopy. Applied Surface Science, 2001. 172 (1) : p. 135-143.

[21] Stewart, P. S. and Costerton, J. W., Antibiotic resistance of bacteria in biofilms. The Lancet, 2001. 358 (9276) : p. 135-138.

[22] Mangalappalli-Illathu, A. K. and Korber, D. R., Adaptive resistance and differential protein expression of Salmonella enterica serovar Enteritidis biofilms exposed to benzalkonium chloride. Antimicrobial agents and Chemotherapy, 2006. 50 (11) : p. 3588-3596.

[23] Maxcy, R. B., Tiwari, N. P. and Soprey, P. R., Changes in Escherichia coli associated with acquired tolerance for quaternary ammonium compounds. Applied Microbiology, 1971. 22 (2) : p. 229-232.

[24] Braoudaki, M. and Hilton, A. Adaptive resistance to biocides in Salmonella enterica and Escherichia coli 0157 and cross-resistance to antimicrobial agents. Journal of Clinical Microbiology, 2004. 42 (1) : p. 73-78.

[25] Langsrud, S., Sundheim, G., and Holck, A., Cross-resistance to antibiotics of Escherichia coli adapted to benzalkonium chloride or exposed to stressinducers. Journal Of Applied Microbiology, 2004. 96 (1): p. 201-208.

[26] Simões, M., Pereira, M. O. and Vieira, M. J. Action of a cationic surfactant on the activity and removal of bacterial biofilms formed under different flow regimes. Water Research, 2005. 39 (2) : p. 478-486.

[27] Shi, X., and Zhu,X., Biofilm formation and food safety in food industries. Trends in Food Science and Technology, 2009. 20 (9) : p. 407-413.

[28] Mendonça, R. C. S., Morelli, A. M. F., Pereira, J. A. M., de Carvalho, M. M. and de Souza, N. L., Prediction of Escherichia coli O157: H7 adhesion and potential to form biofilm under experimental conditions. Food Control, 2012. 23(2): p.389-396. 